\title{
COHERENCE and BACKSCATTER BASED CROPLAND MAPPING USING MULTI- TEMPORAL SENTINEL-1 with DYNAMIC TIME WARPING
}

\author{
Narin, Omer Gokberk ${ }^{1}{ }^{*}$, Abdikan, Saygin ${ }^{2}$, Bayik, Caglar ${ }^{3}$, Sekertekin, Aliihsan ${ }^{4}$, Delen, Ahmet ${ }^{5}$, Balik Sanli, Fusun ${ }^{6}$
}

\begin{abstract}
${ }^{1}$ Department of Geomatics Engineering, Afyon Kocatepe University, Turkey - gokberknarin@aku.edu.tr
${ }^{2}$ Department of Geomatics Engineering, Hacettepe University, Turkey - sayginabdikan@ hacettepe.edu.tr ${ }^{3}$ Department of Geomatics Engineering, Zonguldak Bulent Ecevit University, Turkey - caglarbayik@beun.edu.tr ${ }^{4}$ Department of Geomatics Engineering, Cukurova University, Turkey - asekertekin@cu.edu.tr

${ }^{5}$ Department of Geomatics Engineering, Tokat Gaziosmanpasa University, Turkey - ahmet.delen@ gop.edu.tr

${ }^{6}$ Department of Geomatics Engineering, Yildiz Technical University, Turkey - fbalik@yildiz.edu.tr
\end{abstract}

\section{Youth Forum}

KEY WORDS: Cropland Mapping, Sentinel-1, Coherence, Backscatter, Dynamic Time-Warping.

\begin{abstract}
:
Cropland mapping is an important inventory for food security and decision making operated by governments. Crop mapping is used to identify the croplands and their spatial distribution. For a reliable analysis and forecast for projection, multi-temporal data play a key role. Even current open and frequent optical satellite data such as Sentinel-2 and Landsat support monitoring, they are not always operational due to atmospheric conditions (rain, cloud cover, haze, etc.). On the other hand, Synthetic Aperture Radar (SAR) satellites provide alternative data sets compared to optical satellites since they can acquire images under all weather conditions. In this study, an annual cropland monitoring study is conducted using Sentinel-1 SAR. For the investigation, Tokat Province an agricultural region of Turkey, where the main source of income is agriculture, was selected. There are 4 different vegetation species (wheat, sunflower, sugar beet, corn) in the study area. Sentinel-1 data was used to generate time-series of each class and phenological structures of the crops. In this context, backscatter images of both vertical-vertical (VV) and vertical-horizontal (VH) polarized data, and coherence of both VV and VH were produced from Sentinel-1 data. Time-Weighted Dynamic Time-Warping (TWDTW) classification approach was used over cropland. The produced time-series are classified under different scenarios. The results showed that only coherence has provided higher accuracies about $81 \%$ compared to using only backscatter images as $49 \%$.
\end{abstract}

\section{INTRODUCTION}

The world's population is increasing rapidly, and the projection for the next 30 years shows an increase of about 2 billion people. One of the consequences is that increase of people's desire to reach foods with high added value increases the demand for food (Fróna et al., 2019). Owing to the fact that monitoring of croplands and yield estimation has become very important for sustainable agriculture activities. Moreover, according to the Sustainable Development Goals (SDGs) of the United Nations, achieving sustainable agriculture is one of the targets of SDG 2, which is called "End hunger, achieve food security and improved nutrition and promote sustainable agriculture."

Among the crops, wheat is one of the main crop produced for food. Sunflower is the third crop that is produced widely in the world among the oil crops. Sugar beet is one of the main crop for sugar production. Turkey is the tenth country leading wheat production and fifth largest sugar beet producer (FAO 2020). Thus, crop monitoring is important for crop trade in the global market. To this aim, a location was chosen where these three crops are growing for continuous monitoring of crops.

In the literature, many methods have been used for the classification and monitoring of croplands. One of the challenges of crop mapping is even the crops have different phenology and growing periods it might be difficult to distinguish them in case of the similarities in different growing stages (Narin et al., 2018). Additionally, smallholder farmers can plant another crop after early harvest crops especially in the summer season. However, this new crop type may also be mixed with other cultivated products. Because of these reasons, long-term monitoring of agricultural fields is required.

The potential of the optical data for the crop mapping is well established (Forkuor et al., 2018; Immitzer et al., 2016; Noi and Kappas 2018). Sentinel-2 also provides a long-term dataset with a short revisit time. On the other hand, SAR has the sensitivity to the vegetation biophysical properties and it also has the ability to acquire data over cloudy days, which is an important role against optical monitoring. Various approaches were used with SAR data for the crop classification such as decision tree and naïve Bayes classifier on backscatter data of Sentinel-1 (Xu et al., 2019), extreme gradient boosting with multi-temporal Radarsat-2 Polarimetric SAR (POLSAR) data (Ustuner et al., 2019). There are also studies that combined both optical and SAR images together (Ienco et al., 2019; Tricht et al., 2019; Veloso et al., 2017).)

In most cases, backscatter values are the main inputs for image classification. Some of the current studies also used the advantage of short-time repeat-pass of Sentinel-1 to determine time series of coherence for crop monitoring (Kavats et al. 2019, Khabbazan et al 2019). The coherence is derived from two complex SAR images and composed of information gathered from both phase and amplitude. Low coherence values indicate the decorrelation between the images which might be due to the changes of the scatterers (Kavats et al., 2019). Tamm et al. (2016) showed the feasibility of 12 days Sentinel-1 pairs for grassland mowing. Kavats et al. (2019) studied detection of harvesting date using backscatter and coherence of 12 days Sentinel-1 dataset. 
Khabbazan et al. (2019) investigated the relationship between ground measurements and time-series of backscatter and coherence obtained from Sentinel-1. Even these studies showed promising results for crop monitoring investigation on crop classification, using long-term phenological stages and coherence data is less studied.

Csillik et al. (2019) classified crops area using different scenarios in Dynamic Time-Warping (DTW). They made the classification in different areas and using the Sentinel-2 image. As a result, they reported good results in the classification without time constraints. Olfindo et al. (2020) classified sugarcane parcels using the DTW technique and backscatter of Sentinel-1 data. As a result of the study, they obtained $92.75 \%$ overall accuracy. Besides, they stated that it is promising in the classification of seasonal crops. Lie and Bijker et al. (2019) used backscatter (VV and $\mathrm{VH}$ ) and decomposition features (entropy, angle, and anisotropy) of Sentinel-1 with Time-Weighted Dynamic TimeWarping (TWDTW) for the classification of vegetables.

In this study, the objective is to create crop mapping using only time-series of Sentinel-1 data.

The contributions of the study are given as below;

- to our knowledge this study is the first that examines the contribution of coherence obtained from multitemporal Sentinel-1 satellite on the classification of crops for smallholder farming using TWDTW. For the analysis, 25 images were acquired from Sentinel-1A and $-1 \mathrm{~B}$ satellites in 6 days repeat-pass.

- we explore the feasibility of using time series of coherence for crop mapping.

- we extract the second crop type (corn) after harvesting the first crop (wheat) using time series and TWDTW.

\section{STUDY AREA AND DATA SET}

\subsection{Study Area}

The study area is a cropland region in Tokat province (Figure 1). It has the characteristics of a transition climate between the Black Sea climate and the climate in Central Anatolia (semi-arid continental climate). The average altitude is $710 \mathrm{~m}$., and the average temperature is $11.7^{\circ} \mathrm{C}$ (Url-1). The main livelihood of the region is agriculture, and the main crops grown are wheat, sunflower, sugar beet, and corn. The life cycle of the plant species cultivated is between April and September in the region. The general annual cultivated products in the study area are shown in Figure 1.
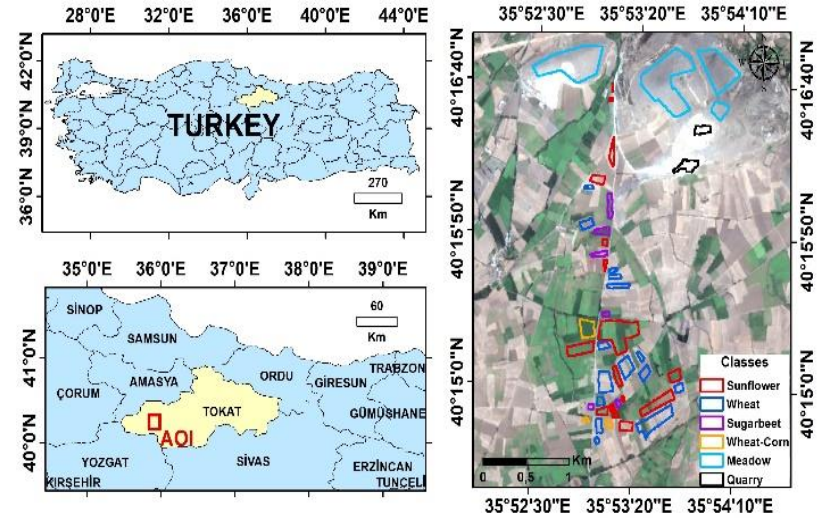

Figure 1. Illustration of the study area and annual cultivated

\subsection{Sentinel-1 Data} products.

Sentinel-1A and -1B provide C-band SAR images and offer short-term data acquisition with 6 days revisit time. For this study, ascending orbit direction data were collected between 18 April 2018 and 15 September 2018. A total of 25 Interferometric Wide (IW) mode and Single Look Complex (SLC) images are processed. Each image has VV and $\mathrm{VH}$ polarization. For the analysis, both $\mathrm{VV}$ and $\mathrm{VH}$ polarized data are used. The incidence angle of the data is $30.57^{\circ}$ and $46.09^{\circ}$ for near and far incidence respectively.

\section{METHODOLOGY}

The methodology of the study is composed of four main steps; (1) pre-processing of SAR images to produce backscatter and coherence images, (2) time series extraction, (3) classification with TWDTW, and (4) accuracy analysis.

\subsection{Pre-processing of SAR images}

The six-day sequential SAR data are acquired through the ESA's open access hub service (https://scihub.copernicus.eu/dhus/\#/home). For all images, the Terrain Observation with Progressive Scans SAR (TOPSAR) split, co-registration, orbit correction, backgeocoding, interferogram and coherence production, TOPSAR deburst, and terrain correction steps were applied to create coherence map and backscatter values. Concerning the extraction of the backscattering coefficient $\left(\sigma^{\circ}\right)$, radiometric calibration was applied before TOPSAR deburst step. Range Doppler Terrain Correction approach was implemented for geometric correction with SRTM 1 Arc-Second HGT data. Finally, linear backscatter values were converted to decibel $(\mathrm{dB})$ unit using the equation (1) below;

$\sigma_{\mathrm{dB}}=10 \cdot \log _{10}\left(\sigma^{\circ}\right)$

The coherence feature indicates the cross-correlation coefficient between two complex SAR images and expressed as $\gamma$, and can be calculated from the equation (2). Coherence values range between zero (minimum correlation) and one (maximum correlation).

$\gamma=\frac{\left|\left(S_{1} S_{2}^{*}\right)\right|}{\sqrt{\left(\left(S_{1} S_{1}^{*}\right)\left(S_{2} S_{2}^{*}\right)\right)}}$

where $S_{1}$ and $S_{2}=$ complex SAR image pair

$*=$ denotes complex conjugation

$\langle=$ indicates a spatial averaging operation 
All the pre-processing steps are applied using Sentinel Application Platform (SNAP) software.

\subsection{Dynamic Time Warping}

DTW is based on the similarity of the time-dependent series. Time-Weighted DTW (TWDTW), which is a variance version of DTW, is used in cropland classification in this study (Maus et al. 2016b). It is written in R language, which is named dtwsat (Maus et al. 2016a). The Dtwsat package provides pixel level classification using satellite image datasets. In the DTW classification method, it does not calculate the stage differences in time series. However, phase offset can occur in plant phenological stages. These weights were taken into account when creating the TWDTW algorithm (Maus et al. 2016b). Time series were created with the coherence and backscatter values obtained from Sentinel-1 data. The results were obtained by classifying with different input data to test their contribution (Table-1). The sizes of the selected classes for the classification are wheat-corn (3.4 ha.), wheat (18.86 ha.), sugar beet (4.06 ha.) meadow (53.86 ha.) quarry (3.48 ha.) sunflower ( 24.98 ha.). A total of 310 pixels are used for the image classification. $80 \%$ of it used for training and $20 \%$ of the dataset is used for validation. For the accuracy analysis error matrix that shows the misclassification and agreement between the reference and the classified image based overall accuracy was used (Csillik et al 2019). In classification, frequency $=1$ was used for temporal patterns, and $\beta=50 \alpha=0.1$ for logistic TWDTW.

\begin{tabular}{|cccl|}
\hline $\begin{array}{l}\text { Classifi- } \\
\text { cations }\end{array}$ & $\begin{array}{c}\text { No. of input } \\
\text { data }\end{array}$ & $\begin{array}{c}\text { No. of input } \\
\text { variables }\end{array}$ & $\begin{array}{l}\text { Description of } \\
\text { variables }\end{array}$ \\
\hline 1 & 24 & 1 & $\Upsilon_{\mathrm{VV}}$ \\
2 & 24 & 1 & $\Upsilon_{\mathrm{VH}}$ \\
3 & 48 & 2 & $\Upsilon_{\mathrm{VV}}+\Upsilon_{\mathrm{VH}}$ \\
4 & 25 & 1 & $\sigma_{\mathrm{VH}}$ \\
5 & 25 & 1 & $\sigma_{\mathrm{VV}}$ \\
6 & 50 & 2 & $\sigma_{\mathrm{VH}}+\sigma_{\mathrm{V}}$ \\
7 & 98 & 4 & $\sigma_{\mathrm{VH}}+\sigma_{\mathrm{V}}+\Upsilon_{\mathrm{VV}}+\Upsilon_{\mathrm{VH}}$ \\
\hline
\end{tabular}

Table 1. Input data of experiments for croplands classification

\section{RESULTS AND DISCUSSIONS}

Time series was created by smoothing the samples selected among the classes for the cropland classification (Figure 2). For each class, time series of backscatter and coherence values were extracted. In the results of backscatter, it is clear that $\sigma_{\mathrm{VH}}$ has higher values than $\sigma_{\mathrm{vv}}$. In general, their behaviors are similar; however, in the wheat area, the $\sigma_{\mathrm{VH}}$ shows a rapid decline after June compared to the $\sigma \mathrm{vv}$.
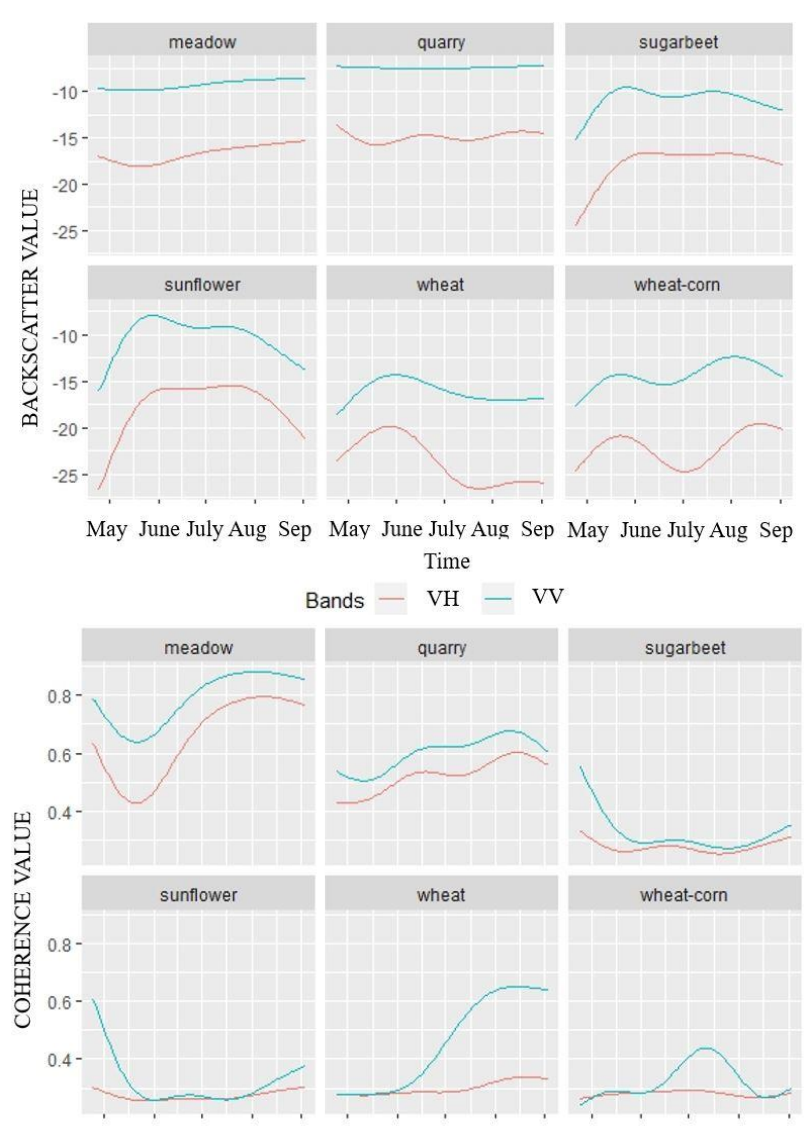

May June July Aug Sep May June July Aug Sep May June July Aug Sep Time

Bands - VH - VV

Figure 2. Time series of backscatter and coherenceConsidering the coherence time series results, the meadow and quarry indicate an identical response to $\Upsilon_{\mathrm{VH}}$ and $\Upsilon_{\mathrm{Vv}}$. In other crops, it is also clear that $\Upsilon_{\mathrm{VV}}$ has higher sensitivity than $\Upsilon_{\mathrm{VH}}$. In the time series depending on the phenological developments, $\Upsilon_{\mathrm{Vv}}$ shows change, whereas $\Upsilon_{\mathrm{VH}}$ is almost stable.

The classification approach is applied to seven scenarios which have different variables of coherence and backscatter images (Table 1). The results of coherence solely showed better results than backscatter values (Table 2). Comparing the individual performances of the polarizations, $\Upsilon_{\mathrm{Vv}}$ achieved $18 \%$ higher accuracy than $\Upsilon_{\mathrm{VH}}$. The combination of both coherence values also increased the accuracy to about $82 \%$.

On the other hand, the results show that backscatter values provided lower accuracies than the coherence values. This is most probably because of that the distribution of backscatter values has a limited range the crops cannot be easily separated (Figure 2, Table 2). Both $\sigma_{v v}$ and $\sigma_{v H}$ presented accuracies lower than $45 \%$, but using both images increased the accuracy by about $4.4 \%$. Including all features also increased the backscatter accuracy but it still revealed lower than the accuracy of the coherence. The classification map that gives the best results according to the overall accuracy is given in Figure 3. As a footnote, the similarity between sugar beet and sunflower classes, especially in VV, caused the classes to be mixed. 


\begin{tabular}{|cc|}
\hline Variables of classifications & Overall accuracy \\
\hline$\Upsilon_{\mathrm{VH}}$ & 0.61 \\
$\Upsilon_{\mathrm{VV}}$ & 0.79 \\
$\Upsilon_{\mathrm{VV}}+\Upsilon_{\mathrm{VH}}$ & $\mathbf{0 . 8 2}$ \\
$\sigma_{\mathrm{VH}}$ & 0.44 \\
$\sigma_{\mathrm{VV}}$ & 0.40 \\
$\sigma_{\mathrm{VV}}+\sigma_{\mathrm{VH}}$ & 0.49 \\
$\sigma_{\mathrm{VV}}+\sigma_{\mathrm{VH}}+\Upsilon_{\mathrm{VV}}+\Upsilon_{\mathrm{VH}}$ & 0.52 \\
\hline
\end{tabular}

Table 2. Overall accuracies of the classifications under the various conditions of the variables.

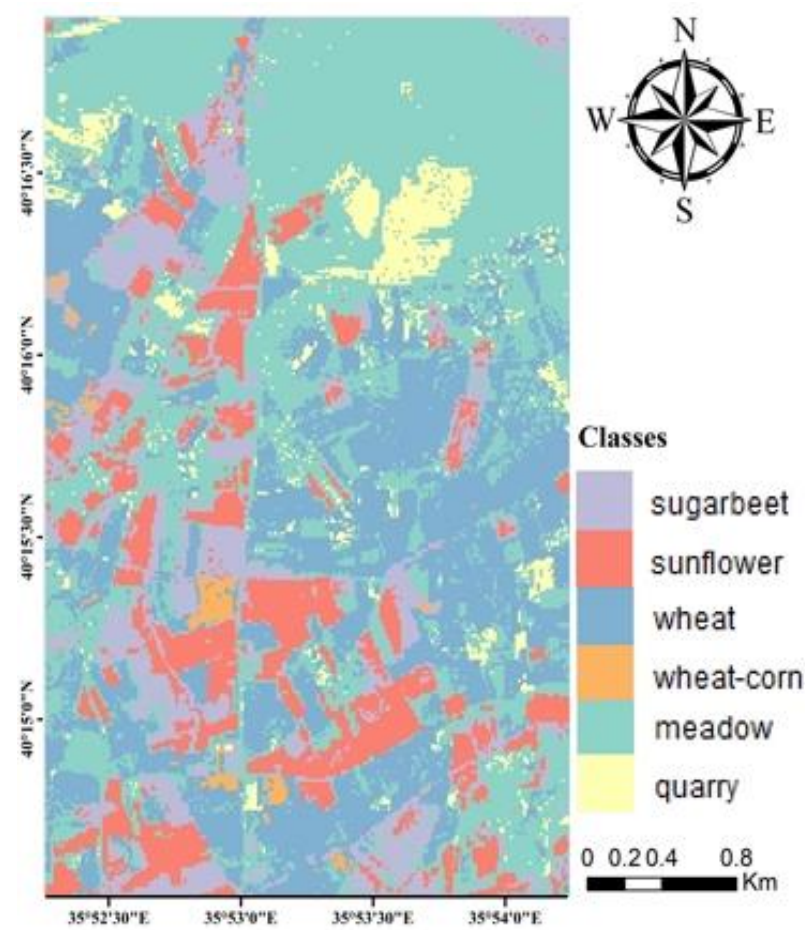

Figure 3. Cropland map classified by $\Upsilon_{\mathrm{VV}}+\Upsilon_{\mathrm{VH}}$, according to TWDTW

It is observed that the corn plant is planted after the harvest in some wheat cultivated fields. Even these fields show similar values till July, an increase in backscatter values and a sharp decrease in coherence values are visible afterward for the wheatcorn fields (Figure 2).

Compared to the previous studies, backscatter values gave lower results which might be due to the amount of crop parcel and crop number. Olfindo et al. (2020) achieved 92\% accuracy for sugarcane and non-sugarcane plantation mapping using a stack of dual-polarized backscatter of Sentinel-1. The study of Li and Bijker (2019) resulted in $80 \%$ overall accuracy using a combination of backscatter and decomposition. As the study of TWDTW on SAR data is not applied widely, this paper shows the contribution of coherence for crop mapping of smallholder farms. The results also presented that after early harvesting of some fields a second crop as corn is planted and these fields are also extracted through the TWDTW approach.

\section{CONCLUSIONS}

The aim of this study is to determine crop mapping using timeseries of remote sensing data. The context relies on utilizing only Sentinel-1 data without optical data or additional data. Considering the results, just coherence provided the highest accuracy that reached up to about $82 \%$. However, the classifications with the backscatter gave worse results. Because, most probably, the backscatter values were in a narrower range. This has increased the similarity of classes in crops. In addition, the similarity between sugar beet and sunflower classes, especially in VV, caused the classes to be mixed. The time series formed according to coherence better represented the differences in the classes in the classification.

Time series can be differentiated with different smoothing techniques to eliminate the mixed classes in future studies. It is planned to work with other features of SAR data and the Synergistic use of SAR and optical satellite data to improve the accuracies in the crop mapping on a large scale. The effect of sample size for the classification will be also tested for the following studies.

\section{REFERENCES}

Csillik, O., Belgiu, M., Asner, G.P., Kelly, M., 2019. ObjectBased Time-Constrained Dynamic Time Warping Classification of Crops Using Sentinel-2. Remote Sens. 11, 1257. https://doi.org/10.3390/rs11101257

FAO. 2020. Food Outlook - Biannual Report on Global Food Markets: June 2020. Food Outlook, 1. Rome. https://doi.org/10.4060/ca9509en

Forkuor, G., Dimobe, K., Serme, I., Tondoh, J., E., 2018 Landsat- 8 vs. Sentinel-2: examining the added value of sentinel2's red-edge bands to land-use and land-cover mapping in Burkina Faso, GIScience \& Remote Sensing, 55(3), 331-354, https://doi.org/10.1080/15481603.2017.1370169

Fróna, D., Szenderák, J., Harangi-Rákos, M., 2019. The Challenge of Feeding the World. Sustainability.; 11(20):5816. https://doi.org/10.3390/su11205816

Giacinto, G., Roli, F., 2000. Combination of neural and statistical algorithms for supervised classification of remote-sensing images. Pattern Recognition Letters, 21(5), 385-397. https://doi.org/10.1016/S0167-8655(00)00006-4

Ienco, D., Interdonato, R., Gaetano, R., Minh, D.H.T. 2019. Combining Sentinel-1 and Sentinel-2 Satellite Image Time Series for land cover mapping via a multi-source deep learning architecture. ISPRS J. Photogramm. Remote Sens. 158, 11-22 https://doi.org/10.1016/j.isprsjprs.2019.09.016

Immitzer, M., Vuolo, F., Atzberger, C., 2016. First Experience with Sentinel-2 Data for Crop and Tree Species Classifications in Central Europe. Remote Sensing. 8(3):166. https://doi.org/10.3390/rs8030166

Kavats, O.; Khramov, D.; Sergieieva, K.; Vasyliev, V. 2019 Monitoring Harvesting by Time Series of Sentinel-1 SAR Data. Remote Sens., 11, 2496.

https://doi.org/10.3390/rs11212496 
Khabbazan, S.; Vermunt, P.; Steele-Dunne, S.; Ratering Arntz, L.; Marinetti, C.; van der Valk, D.; Iannini, L.; Molijn, R.; Westerdijk, K.; van der Sande, C. 2019. Crop Monitoring Using Sentinel-1 Data: A Case Study from The Netherlands. Remote Sens., 11, 1887. https://doi.org/10.3390/rs11161887

Martellozzo, F., Ramankutty, N., Hall, R.J. Price, T., D., Purdy, B., Friedl, M., A.i 2015. Urbanization and the loss of prime farmland: a case study in the Calgary-Edmonton corridor of Alberta. Reg Environ Change 15, 881-893 https://doi.org/10.1007/s10113-014-0658-0

Maus, V., Câmara, G., Appel, M., Pebesma, E. 2016a. dtwSat: Time-weighted dynamic time warping for satellite image time series analysis in R. Journal of Statistical Software, 1-30. https://doi.org/10.18637/jss.v088.i05

Maus, V., Câmara, G., Cartaxo, R., Sanchez, A., Ramos, F.M., de Queiroz, G.R. A., 2016b. Time-Weighted Dynamic Time Warping Method for Land Use and Land Cover Mapping. IEEE J. Sel. Top. Appl. Earth Obs. Remote Sens. 9, 3729-3739. http://doi.org//10.1109/JSTARS.2016.2517118

Narin O.G., Delen A., Abdikan D. 2018. Determination of Agricultural Crop Types Using Sentinel-2a Data. VII. Remote Sensing and GIS Symposium, 18-21 Sept 2018, Eskişehir, Turkey. http://dx.doi.org/10.15659/uzalcbs2018.7286

Noi, T, P., Kappas, M., 2018. Comparison of Random Forest, kNearest Neighbor, and Support Vector Machine Classifiers for Land Cover Classification Using Sentinel-2 Imagery. Sensors. 18(1), 18. https://doi.org/10.3390/s18010018

Olfindo, Jr. N. T., de la Cruz., R. M., Borlongan, N. J. B., Marciano Jr., J. J. S., Olalia, L. C., 2020. Sugarcane Plantation Mapping Using Dynamic Time Warping From Multi-Temporal Sentinel-1a Radar Images. ISPRS Int. Arch. Photogramm. Remote Sens. Spat. Inf. Sci. 519-524, V-3-2020.

https://doi.org/10.5194/isprs-annals-V-3-2020-519-2020

Sekertekin, A., Arslan, N., 2019. Discovering the Changes in Land Surface Temperature Caused by the Conversion of Agricultural Lands to Residential and Urban Use. In 2019 9th International Conference on Recent Advances in Space Technologies (RAST), 393-398. IEEE.

https://doi.org/10.1109/RAST.2019.8767894

Shah, C. A., Varshney, P. K., Arora, M. K. 2007. ICA mixture model algorithm for unsupervised classification of remote sensing imagery. International Journal of Remote Sensing, 28(8), 1711-1731 https://doi.org/10.1080/01431160500462121

Skriver, H., Mattia, F., Satalino, G., Balenzano, A., Pauwels, V.R.N., Verhoest, N.E.C., Davidson, M., 2011 Crop Classification Using Short-Revisit Multitemporal SAR Data. IEEE J. Sel. Top. Appl. Earth Obs. Remote Sens. 4, 423-431. https://doi.org/10.1109/JSTARS.2011.2106198

Tomppo, E., Antropov, O., Praks, J, 2019. Cropland Classification Using Sentinel-1 Time Series: Methodological Performance and Prediction Uncertainty Assessment. Remote Sensing. 11(21):2480. https://doi.org/10.3390/rs11212480

Xu, L., Zhang, H., Wang, C., Zhang, B., Liu, M., 2019. Crop Classification Based on Temporal Information Using Sentinel-1
SAR Time-Series Data. Remote Sensing. 11(1):53. https://doi.org/10.3390/rs11010053

Tricht, K, V., Gobin, A., Gilliams, S., Piccard, I., 2018. Synergistic Use of Radar Sentinel-1 and Optical Sentinel-2 Imagery for Crop Mapping: A Case Study for Belgium. Remote Sensing. 10(10):1642. https://doi.org/10.3390/rs10101642

M. Ustuner, F. B. Sanli, S. Abdikan, G. Bilgin and C. Goksel, "A Booster Analysis of Extreme Gradient Boosting for Crop Classification using PolSAR Imagery," 2019 8th International Conference on Agro-Geoinformatics (Agro-Geoinformatics), Istanbul, Turkey, 2019, pp. 1-4,

https://doi.org/10.1109/Agro-Geoinformatics.2019.8820698.

Veloso, A., Mermoz, S., Bouvet, A., Le Toan, T., Planells, M., Dejoux, J.-F., Ceschia, E., 2017. Understanding the temporal behavior of crops using Sentinel-1 and Sentinel-2-like data for agricultural applications. Remote Sens. Environ. 199, 415-426 https://doi.org/10.1016/j.rse.2017.07.015

Tamm, T., Zalite, K., Voormansik, K. Talgre, L,. 2016 Relating Sentinel-1 Interferometric Coherence to Mowing Events on Grasslands. Remote Sens. , 8, 802.

https://doi.org/10.3390/rs8100802

URL-1 https://web.zile.bel.tr/ 